\title{
PENAMBAHAN SWISS BALL PADA CORE STABILITY EXERCISE DAN CORE STABILITY EXERCISE DAPAT MENINGKATKAN LINGKUP GERAK SENDI DAN AKTIVITAS FUNGSIONAL PADA PETANI WANITA DENGAN LOW BACK PAIN NON SPESIFIK DI KOTA TOMOHON
}

\author{
Novtiyas Maria Pombu ${ }^{1}$, Susy Purnawati ${ }^{2}$, S. Indra Lesmana ${ }^{3}$, Alex Pangkahila ${ }^{4}$, Luh Made Indah \\ Sri Handari Adiputra ${ }^{5}$, Wahyuddin ${ }^{6}$ \\ ${ }^{1}$ Program Studi Magister Fisiologi Olahraga Universitas Udayana Denpasar Bali \\ 2,4,5Fakultas Kedokteran Universitas Udayana Denpasar Bali \\ ${ }^{3,6}$ Fakultas Fisioterapi Universitas Esa Unggul Jakarta
}

\begin{abstract}
ABSTRAK
Latar Belakang: Low Back Pain non spesifik adalah nyeri punggung bawah yang disebabkan oleh gangguan atau kelainan pada unsur muskuloskeletal tanpa disertai dengan gangguan neurologis yang dapat timbul akibat adanya potensi kerusakan jaringan yang menyebabkan terjadinya keterbatasan LGS dan penurunan aktivitas fungsional. Tujuan: Untuk membuktikan bahwa penambahan Swiss ball pada core stability exercise dan core stability exercise dapat meningkatkan lingkup gerak sendi dan aktivitas fungsional pada petani wanita dengan low back pain non spesifik di Kota Tomohon. Metode: Penelitian ini menggunakan metode true eksperimental, dengan rancangan penelitian pre-test and post-test group design. Penelitian ini menggunakan 18 subjek yang dibagi menjadi 2 kelompok, Kelompok Perlakuan I dengan core stability exercise dan Kelompok Perlakuan II penambahan Swiss ball pada core stability exercise. Ke dua kelompok perlakuan diberikan pelatihan 3 kali seminggu selama 4 minggu. Alat ukur yang digunakan untuk mengukur LGS lumbal adalah modified-modified schober test dan disabilitas lumbal adalah modified Oswestry disability index. Hasil Penelitian: Untuk hasil paired sample t-test Kelompok Perlakuan I LGS fleksi dan ekstensi didapatkan hasil $\mathrm{p}=0,000(\mathrm{p}<0,05)$ dan Kelompok Perlakuan II LGS fleksi dan ekstensi didapatkan hasil $\mathrm{p}=0,000(\mathrm{p}<0,05)$. Penurunan nilai modified ODI pada Kelompok Perlakuan I didapatkan hasil $\mathrm{p}=0,000(\mathrm{p}<0,05)$ dan Kelompok Perlakuan II didapatkan hasil $\mathrm{p}=0,000(<0,05)$. Hasil independent $t$-test menunjukkan LGS fleksi pada Kelompok Perlakuan I dengan nilai $\mathrm{p}=0,879$ $(>0,05)$. Nilai LGS ekstensi pada Kelompok Perlakuan I dengan nilai $p=0,733(>0,05)$. Hasil uji hipotesis menunjukkan penurunan disabilitas lumbal dapat dinilai modified ODI pada Kelompok Perlakuan I dengan nilai $\mathrm{p}=0,891$ (>0,05). Kesimpulan: Secara statistik tidak ada beda penambahan Swiss ball pada core stability exercise dan core stability exercise dalam meningkatkan lingkup gerak sendi dan aktivitas fungsional pada petani wanita dengan low back pain non-spesifik.
\end{abstract}

Kata Kunci: Low back pain non-spesifik, Swiss ball, core stability exercise, modified-modified Schober test, modified Oswestry disability index. 


\title{
SWISS BALL ADDITIONAL ON CORE STABILITY EXERCISE AND CORE STABILITY EXERCISE MAY IMPROVING RANGE OF MOTION AND FUNCTIONAL ACTIVITY TO AMONG FEMALE FARMER WITH NON-SPECIFIC LOW BACK PAIN IN TOMOHON CITY
}

\begin{abstract}
Background: Non-specific low back pains are low back pain caused by disorders or abnormalities in the musculoskeletal element without the presence of neurological disorders that can arise due to potential tissue damage leading to range of motion limitations and decreased functional activity. Objective: To prove that the addition of Swiss ball to core stability exercise and core stability exercise can improve the range of motion and functional activity in female farmers with non-specific low back pain in Tomohon City. Method: This research used true experimental method, with pretest and post-test group design. This study used 18 subjects divided into 2 groups, Treatment Group I with core stability exercise and Treatment Group II addition of Swiss ball on core stability exercise. Both treatment groups were given training 3 times a week for 4 weeks. The measuring instrument used to measure lumbar LGS is the modified-modified Schober test and lumbar disability is a modified Oswestry disability index. Results: For the result of paired sample t-test of treatment group I LGS flexion and extension obtained $\mathrm{p}=0.000(\mathrm{p}<0.05)$ and treatment group II LGS flexion and extension obtained result $p=0.000(p<0.05)$. The decrease of modified ODI value in treatment group I obtained $p=0.000(p<0.05)$ and treatment group II was obtained $p=0.000(<0.05)$. The independent t-test results showed LGS flexion in treatment group I with $p=0.879(>0.05)$. The value of LGS extension in treatment group I with p value $=0.733(>0.05)$. The result of hypothesis test showed that the decrease of lumbar disability can be evaluated modified ODI in treatment group I with $\mathrm{p}=$ 0.891 (>0.05). Conclusions: There is no statistically different Swiss ball addition to the core stability exercise and core stability exercise in increasing the range of motion and functional activity in female farmers with non-specific low back pain.
\end{abstract}

Keywords: Non-specific low back pain, Swiss ball, core stability exercise, modified-modified Schober test, modified Oswestry disability index.

\section{PENDAHULUAN}

Manusia dalam kehidupan sehari-hari dituntut untuk melakukan berbagai macam aktivitas baik itu duduk, berdiri, berjalan, bekerja, berolahraga dan lain-lain. Aktivitas tersebut dipengaruhi oleh berbagai faktor, ada yang bersifat menguntungkan maupun yang merugikan yang dapat menyebabkan terjadinya gangguan fungsional. Faktor tersebut antara lain adalah faktor fisiologis di antaranya sikap tubuh yang kurang baik dan postur kerja yang tidak ergonomis. Gangguan sistem musculoskeletal sering dialami beberapa pekerja di tempat kerja. Pekerjaan yang dilakukan dengan sikap kerja statis dan secara terus menerus dalam waktu lama dapat berpotensi menimbulkan musculoskeletal disorder (MSD). ${ }^{1}$ Salah satu contoh MSDs yang banyak terjadi yaitu nyeri pada region punggung bagian bawah atau sering disebut Low Back Pain (LBP).

LBP adalah suatu sindrom nyeri yang terjadi pada region punggung bagian bawah yang merupakan akibat dari berbagai sebab. LBP non-spesifik adalah nyeri punggung bawah yang disebabkan oleh gangguan atau kelainan pada unsur muskuloskeletal tanpa disertai dengan gangguan neurologis. ${ }^{2}$ Gangguan ini paling banyak ditemukan di tempat kerja, terutama pada orang yang beraktivitas dengan posisi tubuh yang salah. ${ }^{3}$

Prevalensi penyakit musculoskeletal tertinggi berdasarkan pekerjaan adalah pada petani, nelayan atau buruh yaitu 31,2\%. ${ }^{4}$

Data Badan Pusat Statistik (BPS) hingga tahun 2010 tercatat tenaga kerja petani di Indonesia mencapai 107,4 juta orang. Kota Tomohon merupakan suatu daerah yang 
berkembang menjadi kota yang masih memiliki sifat agraris. Disebut agraris karena sebagian besar penduduk Kota Bunga (julukan lain Tomohon) ternyata bermata pencarian petani (Khusus tanaman pangan seperti padi, sayur-sayuran dan juga sebagai petani bunga). Jumlah petani di Kota Tomohon sebanyak 7.424 orang, 7,8 \% penduduk Kota Tomohon bekerja sebagai petani. ${ }^{5}$ Berdasarkan survei yang dilakukan pada petani, didapatkan data $30 \%$ petani mengeluh menderita LBP. Ditemukan $90 \%$ bukan karena kelainan organik pada kasus LBP, tetapi kebanyakan kasus LBP di sebabkan oleh kesalahan postur tubuh saat melakukan pekerjaan. Postur kerja membungkuk yang lama akan menyebabkan ketegangan otot di daerah punggung. Pada saat membungkuk dibutuhkan ketahanan otot yang besar pada seorang pekerja saat melakukan pekerjaanya, hal tersebut akan memicu terjadinya keluhan musculoskeletal akibat pembebanan berlebih pada tulang belakang. ${ }^{6}$

Latihan Swiss ball exercise dan core stability exercise, melibatkan pengaturan kembali pada aktivasi pola kontraksi dari otot tranversus abdominis dan multifidus lumbal untuk memberikan support pada segmen lokal. Ketika otot tranversus abdominis dan multifidus lumbal bekerja secara normal, akan meningkatkan ketegangan pada fascia thoracolumbal yang berfungsi sebagai penyangga, dan memberikan stabilitas pada tulang belakang. Hal ini lah yang menyebabkan terjadinya penurunan nyeri dan peningkatan aktivitas fungsional dari penderita LBP non spesifik. Pada penelitian di atas penggunaan core stability exercise dengan Swiss ball dapat mengurangi nyeri dan disabilitas fungsional secara signifikan dibandingkan dengan core stability exercise.

Judul dari penelitian ini yakni "Penambahan Swiss Ball pada Core Stability Exercise dan Core Stability Exercise dapat Meningkatkan LGS dan Aktivitas Fungsional pada Petani Wanita Dengan LBP Non Spesifik", judul ini penulis ambil dengan melihat permasalahan pada latar belakang masalah di atas.

Hipotesis penelitian ini adalah (1) Penambahan Swiss ball pada core stability exercise dan core stability exercise dapat meningkatkan LGS pada LBP non spesifik petani di Kota Tomohon. (2) Penambahan Swiss ball pada core stability exercise dan core stability exercise dapat meningkatkan aktivitas fungsional pada LBP non spesifik petani di Kota Tomohon.

\section{METODE PENELITIAN}

\section{A. Rancangan Penelitian}

Rancangan Penelitian yaitu penelitian eksperimental, dengan metode pre-test and post-test group design. Desain penelitian ini Membandingkan perlakuan antara 2 kelompok. Kelompok Perlakuan 1 dengan penambahan core stability exercise dan kelompok Perlakuan 2 dengan Swiss ball pada core stability exercise.

\section{B. Tempat dan Waktu Penelitian}

Tempat serta waktu penelitian di kelurahan Tara-tara 3, Kecamatan Tomohon Barat, Kota Tomohon. Waktu penelitian dimulai dengan persiapan penelitian (Januari 2018) sampai penyusunan laporan (Juni 2018).

\section{Populasi dan Sampel}

Populasi target penelitian adalah pasien penderita LBP non spesifik yang bekerja sebagai petani di Kota Tomohon. Populasi terjangkau dalam penelitian ini adalah pasienpasien LBP non spesifik yang bekerja sebagai petani dimana sudah memenuhi kriteria inklusi dan eksklusi. Dengan rumus Pocock untuk menentukan besaran sampel, sampel diambil dari populasi yang dilakukan secara acak. ${ }^{7}$

Teknik pengambilan sampel adalah menentukan kelurahan Tara-tara 3 yang akan dijadikan tempat asal sampel. 3 anggota kelompok tani yang masing-masing terdiri dari kelompok tani Berdikari, Suka Maju, Rawingkolo, dan masing-masing kelompok berjumlah 15 orang. Dan total jumlah petani sebagai populasi terjangkau pada penelitian ini adalah 45 orang, yang kemudian diseleksi berdasarkan kriteria eksklusi dan inklusi. Didapatkan 18 sampel penilitian yang telah memenuhi kriteria inklusi dan eksklusi. Kelompok di bagi menjadi dua dengan jumlah 
9 orang pada masing-masing kelompok, secara random alokasi memakai teknik undian pembagian kelompok dilakukan.

\section{Prosedur Penelitian}

Setelah subjek menandatangani informed consent, kemudian masuk pada tahap pelaksanaan. Tahap pelaksanaan: (a) melakukan anamnesis dan pemeriksaan fisik sampel. (b) Menetapkan kelompok perlakuan berdasarkan kriteria inklusi dan eksklusi. (c) Melakukan pengukuran modified-modified Schober test dan modified ODI. (d) Kelompok Perlakuan 1 menerima perlakuan core stability exercise dan Kelompok Perlakuan 2 menerima perlakuan penambahan Swiss ball pada core stability exercise dengan frekuensi 3 kali perminggu selama 4 minggu. (e) Melakukan pengukuran modified-modified Schober test untuk LGS lumbal dan modified ODI untuk Aktivitas fungsional.

\section{E. Analisis Data}

Analisis data untuk pengujian statistik pada penelitian ini adalah uji hipotesis I dan II menggunakan paired sample t-test dan uji Hipotesis III menggunakan independent sample t-test.

\section{HASIL PENELITIAN}

\section{Deskripsi Karakteristik Subjek Penelitian}

Tabel 5.1

Karakteristik sampel menurut umur dan masa kerja petani

\begin{tabular}{lcc}
\hline $\begin{array}{l}\text { Karakteristik } \\
\text { sampel }\end{array}$ & $\begin{array}{c}\text { KP } 1 \\
\text { Rerata } \pm \text { SB }\end{array}$ & $\begin{array}{c}\text { KP } 2 \\
\text { Rerata } \pm \text { SB }\end{array}$ \\
\hline Umur (th) & $44,67 \pm 3,16$ & $47,67 \pm 3,35$ \\
& & \\
Masa Kerja & Persentase & Persentase \\
$\leq 20$ Tahun & $3(33,3 \%)$ & $1(11,1 \%)$ \\
> 20 Tahun & $6(66,7 \%)$ & $8(88,9 \%)$ \\
\hline
\end{tabular}

Persentase jenis kelamin subjek penelitian pada Kelompok Perlakuan I dan II masing-masing kelompok sebanyak 9 orang dengan total 18 orang dengan jenis kelamin perempuan.

\section{Uji Normalitas dan Homogenitas data}

Tabel 5.4

Uji Normalitas data

\begin{tabular}{llcc}
\hline modified-modified & & \multicolumn{2}{c}{ Uji } \\
$\begin{array}{l}\text { Schober test } \\
\&\end{array}$ & & KP 1 & KP 2 \\
modified ODI & & nilai p & nilai p \\
\hline LGS Fleksi & Pre & 0,433 & 0,888 \\
& Post & 0,895 & 0,061 \\
LGS Extensi & Pre & 0,368 & 0,341 \\
& Post & 0,257 & 0,327 \\
modified ODI & Pre & 0,478 & 0,807 \\
& Post & 0,226 & 0,480 \\
\hline
\end{tabular}

Tabel 5.5

Uji Homogenitas data

\begin{tabular}{|c|c|c|}
\hline \multicolumn{2}{|c|}{$\begin{array}{l}\text { modified-modified Schober } \\
\text { test } \\
\& \\
\text { modified ODI }\end{array}$} & $\begin{array}{l}\text { Uji Homogenitas } \\
\text { nilai } \mathrm{p} \\
\end{array}$ \\
\hline LGS Fleksi & Pre & 0,822 \\
\hline \multirow{3}{*}{ LGS Extensi } & Post & 0,542 \\
\hline & Pre & 0,078 \\
\hline & Post & 0,941 \\
\hline \multirow[t]{2}{*}{ modified ODI } & Pre & 0,052 \\
\hline & Post & 0,438 \\
\hline
\end{tabular}

Berdasarkan tabel di atas menunjukkan bahwa nilai $\mathrm{p}>0,05$, maka kesimpulan dari hasil di atas adalah data-data tersebut berdistribusi normal dan homogen, jadi uji beda yang digunakan yaitu uji parametrik.

\section{Uji beda nilai modified-modified Schober test dan modified ODI perlakuan sebelum dan sesudah pada ke dua kelompok}

\section{Tabel 5.5}

Nilai modified-modified Schober test

\begin{tabular}{cccc}
\hline & $\begin{array}{c}\text { Sebelum } \\
\text { perlakuan } \\
\text { Rerata } \pm \text { SB }\end{array}$ & $\begin{array}{c}\text { Setelah } \\
\text { Perlakuan } \\
\text { Rerata } \pm \text { SB }\end{array}$ & $\mathrm{p}^{*}$ \\
\hline KP 1 & & & \\
- Fleksi & $2,55 \pm 0,64$ & $2,48 \pm 0,56$ & 0,000 \\
- Ekstensi & $5,14 \pm 0,24$ & $5,12 \pm 0,35$ & \\
KP 2 & & & \\
- Fleksi & $0,83 \pm 0,41$ & $0,86 \pm 0,24$ & 0,000 \\
- Ekstensi & $2,07 \pm 0,13$ & $2,10 \pm 0,14$ & \\
\hline p $^{* *}$ & 0,818 & 0,879 & \\
Keterangan: & &
\end{tabular}

$\mathrm{p}^{*}$ : Hasil uji beda menggunakan paired sample t test

$\mathrm{p}^{* *}$ : Hasil uji beda menggunakan independent sample t test

Berdasarkan tabel di atas hasil uji paired sample $t$ test pada ke dua kelompok 
menunjukkan nilai $\mathrm{p}<0,05$ yang berarti ada perbedaan nilai LGS yang bermakna pada perlakuan core stability exercise dan penambahan Swiss ball pada core stability exercise sebelum dan setelah perlakuan. Terjadi peningkatan LGS Fleksi 49,61\% pada KP I dan 48,43\% pada KP II, serta peningkatan LGS ekstensi $40,09 \%$ pada KP I dan $40,95 \%$ pada KP II.

Hasil uji independent sample $t$ test Kelompok I dan II menujukan nilai $\mathrm{p}>0,05$ artinya tidak didapatkan perbedaan nilai LGS yang bermakna sebelum dan setelah perlakuan core stability exercise dan penambahan Swiss ball pada core stability exercise.

Tabel 5.5

Nilai modified ODI

\begin{tabular}{lccc}
\hline & $\begin{array}{c}\text { Sebelum } \\
\text { perlakuan } \\
\text { Rerata } \pm \text { SB }\end{array}$ & $\begin{array}{c}\text { Setelah } \\
\text { Perlakuan }\end{array}$ & Rerata \pm SB \\
& p* \\
\hline KP 1 Mod. ODI & $28,67 \pm 8,18$ & $26,22 \pm 7,24$ & 0,001 \\
KP 2 Mod. ODI & $32,67 \pm 4,89$ & $25,78 \pm 6,20$ & 0,000 \\
p** & 0,226 & 0,891 & \\
\hline Keterangan: & \\
p*: Hasil uji beda menggunakan paired sample t test \\
p**: Hasil uji beda menggunakan independent sample t test
\end{tabular}

Berdasarkan hasil Tabel di atas maka uji paired sample t test menunjukkan nilai $\mathrm{p}<$ 0.05 pada ke dua kelompok yang berarti ada perbedaan skor modified ODI yang bermakna sebelum dan sesudah perlakuan. Terjadi Penurunan nilai modified ODI $91,45 \%$ pada KP I dan 78,91\% pada KP II.

Hasil uji independent sample t test pada kelompok I dan II menujukan nilai $\mathrm{p}>0,05$ yang berarti tidak ada perbedaan nilai modified ODI yang bermakna sebelum dan setelah perlakuan core stability exercise dan penambahan Swiss ball pada core stability exercise.

\section{PEMBAHASAN}

\section{Peningkatan LGS pada kelompok penambahan Swiss ball pada core stability exercise dan core stability exercise}

Berdasarkan paired t-test disimpulkan bahwa penambahan Swiss ball pada core stability exercise dan core stability exercise dapat meningkatkan LGS.
Saat otot-otot core tidak seimbang hal ini dapat menyebabkan penurunan fleksibilitas trunk. Pada wanita dewasa cenderung memiliki otot-otot abdominal yang lemah dibandingkan dengan otot-otot trunk, sehingga pada saat membungkuk atau bergerak ke arah fleksi akan mengalami kesulitan atau tidak terjadi secara maksimal. Hal ini bisa terjadi karena pada saat fleksi hanya otot-otot trunk yang bekerja menahan agar badan tidak jatuh ke depan sehingga cenderung untuk menarik badan ke belakang. Namun jika kekuatan otototot core seimbang dan stabil, maka fleksibilitas trunk bisa meningkat. Hal ini disebabkan karena pada saat fleksi otot-otot trunk akan bekerja secara eksentrik atau memanjang mempertahankan berat badan sedangkan otot-otot abdominal akan bekerja secara konsentrik atau memendek menahan berat badan ke depan. Sehingga dengan latihan core stability yang diberikan kepada wanita dewasa yang menderita LBP akan meningkatkan kekuatan otot yang akan menyebabkan otot bekerja secara seimbang sehingga gerakan tubuh akan lebih fleksibel bergerak ke segala arah.

Terjadinya kontraksi otot dan gerakan yang berulang pada area spine, pelvis dan hip, itu di pengaruhi oleh gerakan yang dilakukan secara berulang pada core stability exercise. Core stability exercise melibatkan otot obliques eksternal, obliques internal, quadratus lumborum, mulfidus, otot-otot pelvic floor, rectus abdominis, diafragma, erector spine, glutealis dan illopsoas. Saat core stability exercise berlangsung maka pada fungsi otot core, pelvic, spine, hip dan kontrol saraf akan terjadi kombinasi yang berfungsi untuk meningkatkan fleksibilitas trunk. Jika otot core meningkat kekuatanya, maka akan terjadi peningkatan kekuatan otot pula pada daerah hip, knee, dan ankle. Peningkatan kekuatan otot tersebut juga akan meningkatkan fleksibilitas. Hal ini dapat terjadi karena penguluran (stretch) pada otot-otot antagonis, pada saat otot berkontraksi. Secara otomatis, jika ada peningkatan kekuatan otot maka fleksibilitas akan meningkat. ${ }^{8}$

Peningkatan LGS sebagai efek dari penambahan Swiss ball pada core stability exercise yang terjadi karena latihan 
penambahan Swiss ball akan meningkatkan keseimbangan dinamis, yang disebabkan oleh aktifnya proprioseptif sebagai sistem informasi dari sendi dan otot, untuk mengkoordinasi refleks ke otak untuk menjaga keseimbangan sehingga akan terjadi keseimbangan dinamis. Setelah itu akan terjadi aktivasi otot-otot core global dan memperkuat core muscle, sehingga akan memperbaiki stabilitas pada tulang belakang dan terjadi peningkatan LGS pada lumbal. ${ }^{9}$

Pada penelitian ini, peningkatan LGS lumbal memiliki nilai yang tidak jauh berbeda atau relatif sama pada ke dua kelompok perlakuan. Hal ini terjadi karena ke dua kelompok perlakuan sama-sama dapat meningkatkan LGS lumbal pada petani wanita di Kota Tomohon. Dengan jumlah gerakan pada ke dua kelompok adalah 4 gerakan diawali dengan pemanasan selama 5 menit, peregangan ringan, dan setelah melakukan 4 gerakan tersebut, diakhiri dengan pendinginan 5 menit. Keempat Gerakan yang digunakan adalah curl-up, bridging, prone hands, dan front plank. Gerakan pada penambahan swiss ball pada core stability exercise mempunyai gerakan yang relative sama core stability exercise, sehingga jika dilihat dari hasil yang diperoleh tidak berbeda secara signifikan pada ke dua kelompok perlakuan.

Penelitian Sekendiz et al tahun 2010, menunjukkan bahwa latihan penambahan Swiss ball pada core stability exercise, secara signifikan dapat meningkatkan kekuatan otot core, daya tahan, fleksibilitas, dan keseimbangan pada wanita yang menderita LBP. Hal ini terjadi karena adanya aktivasi sistem proprioseptif yang bergantung pada informasi dari sendi dan mengkoordinasi refleks bawah sadar untuk menjaga keseimbangan sehingga terjadi peningkatan kekuatan otot core global dan lokal untuk menjaga stabilitas dari tulang belakang dan meningkatkan LGS. ${ }^{9}$ Sedangkan core stability exercise Pada penelitian Suresh et al tahun 2015, menyatakan bahwa penggunaan core stability exercise menunjukkan hasil statistik yang signifikan dalam menurunkan nyeri, meningkatkan fleksibilitas dan Aktivitas fungsional pada penderita low back pain. Hal ini disebabkan karena pada latihan core stability exercise akan memfasilitasi cokontraksi antara otot abdomen dan otot ekstensor lumbal untuk menjaga stabilitas trunk, sehingga timbul gerakan yang lebih efektif, dan terjadi peningkatan fleksibilitas trunk. ${ }^{10}$ Core stability exercise akan mengaktivasi otot stabilitas tulang belakang global dan segmental, kontraksi yang terkoordinasi serta bersamaan pada otot-otot stabilisasi trunk, menyebabkan trunk akan menjadi stabil, dan LGS meningkat sehingga latihan penambahan Swiss ball pada core stability exercise dan core stability exercise sama-sama dapat meningkatkan LGS lumbal pada petani wanita di Kota Tomohon.

\section{Peningkatan aktivitas fungsional pada kelompok penambahan swiss ball pada core stability exercise dan core stability exercise}

Penelitian ini menemukan bahwa penambahan Swiss ball pada core stability exercise dan core stability exercise dapat menurunkan disabilitas lumbal.

Gangguan yang terjadi pada LBP non spesifik adalah nyeri tekan dan spasme otot pada daerah lumbal, serta keterbatasan saat melakukan suatu gerakan, penurunan mobilitas lumbal tersebut akan mengakibatkan terjadinya penurunan aktivitas fungsional disebabkan oleh terjadinya ketidakseimbangan pada otot abdominal dan paravertebral.

Penurunan disabilitas dengan kata lain peningkatan aktivitas fungsional sebagai efek dari latihan core stability exercise. Hal ini terjadi karena Core stability exercise bertujuan untuk mengaktivasi dan membentuk kontrol neuromuscular otot segmental profunda dan otot stabilitas tulang belakang global untuk menopang tulang belakang melawan beban eksternal. ${ }^{11}$ Pengaruh core stability exercise akan meningkatkan kerja otot superfisial (obliquss externus abdominis, obliquss intenus abdominis, rectus abdominis, quadratus lumborum bagian lateral, dan erector spine) dan otot segmental (tranversus abdominis, multifidus, quadratus lumborum bagian profunda, dan rotator profunda) serta memberikan rigiditas pada otot-otot penopang trunk, yang disebabkan oleh terjadinya 
kontraksi yang terkoordinasi dan bersamaan (co-contraction) dari otot-otot tersebut.

trunk akan menjadi stabil, sehingga postur tegak dapat dipertahankan melawan berbagai gaya yang mengganggu keseimbangan dan memberikan dasar yang stabil. Jika terjadi penguatan pada otot-otot core maka stabilitas pada tulang belakang akan meningkat dan akan memperbaiki postur, serta mencegah terjadinya cedera dan meningkatkan aktivitas fungsional tubuh. ${ }^{11}$

Peningkatan aktivitas fungsional sebagai efek dari latihan penambahan Swiss ball pada core stability exercise. Hal ini terjadi karena penambahan Swiss ball pada core stability exercise bertujuan untuk coactivation pada otot core global dan lokal, pada latihan tersebut terjadi kontraksi otot baik secara isometrik maupun isotonik mengakibatkan sirkulasi darah menjadi lancar dan nutrisi serta $\mathrm{O}_{2}$ ke otot membaik, dengan adanya latihan stabilitas, kerja otot agonis dan antagonis akan menjadi seimbang dan kekuatan otot akan meningkat. Sehingga fleksibilitas, stabilitas sendi dan proprioseptif akan meningkat, serta memungkinkan terjadinya gerakan yang lebih efektif. $^{12}$ Kondisi ini juga akan berpengaruh pada peningkatan Aktivitas fungsional atau penurunan disabilitas lumbal pada LBP non spesifik pada petani wanita.

Penurunan disabilitas lumbal pada penelitian ini memiliki nilai yang relatif sama pada ke dua kelompok perlakuan. Hal ini terjadi karena gerakan yang dilakukan dapat memenuhi komponen postural stability yang berupa gerakan terkoordinasi dan gerakan yang efisien pada ke dua kelompok perlakuan. Ada 4 gerakan pada ke dua kelompok perlakuan diawali dengan pemanasan selama 5 menit, peregangan ringan, dan setelah melakukan 4 gerakan tersebut, diakhiri dengan pendinginan 5 menit. Keempat gerakan yang digunakan adalah curl-up, bridging, prone hands, dan front plank. Dengan dosis latihan dilakukan dengan minggu pertama-6 repetisi, minggu ke dua-9 repetisi, minggu ke 3-12 repetisi, minggu ke 4-15 repetisi, dengan 5-10 detik tahan, dengan istirahat per set 2-3 menit.

Pada penelitian Raj et al tahun 2016, menyatakan bahwa penggunaan Swiss ball pada core stability exercise menunjukkan peningkatan statistik yang signifikan dalam menurunkan nyeri dan disabilitas pada penderita LBP. Hal ini disebabkan oleh, pada saat melakukan latihan Swiss ball responden lebih sering berada pada posisi vertikal dari lantai. Sehingga terjadi aktivasi otot yang menghasilkan stabilisasi trunk karena permukaan yang kurang stabil. Penambahan Swiss ball pada core stability exercise sama baiknya dengan core stability exercise dalam meningkatkan aktivitas fungsional atau menurunkan disabilitas lumbal pada wanita dewasa karena penambahan Swiss ball pada core stability exercise akan mengaktivasi otot penggerak trunk yaitu otot core global dan segmental, yang menimbulkan kekuatan otot pada daerah trunk dan gerakan menjadi efisien sehingga terjadi peningkatan aktivitas fungsional atau penurunan disabilitas lumbal. ${ }^{13}$

Pada penelitian Balakrishnan et al tahun 2016, menyatakan bahwa penggunaan core stability exercise menunjukkan adanya pengaruh yang signifikan dalam menurunkan nyeri dan disabilitas lumbal pada penderita LBP non spesifik. Hal ini terjadi karena adanya aktivasi dari otot core global dan segmental, sehingga gerak pada lumbal menjadi lebih efektif dan terjadi peningkatan pada Aktivitas fungsional. Core stability exercise akan mengaktivasi otot-otot stabilisasi trunk, seperti multifidus, erector spinae, dan abdominal, yang akan mengurangi ketidakseimbangan kerja otot sehingga meningkatkan efisiensi gerak dan meningkatkan aktivitas fungsional atau mengurangi disabilitas lumbal. Hal ini yang menyebabkan penambahan Swiss ball pada core stability exercise serta core stability exercise sama-sama meningkatkan Aktivitas fungsional atau menurunkan disabilitas lumbal pada petani wanita di Kota Tomohon. ${ }^{14}$

Hasil yang didapatkan berupa peningkatan aktivitas fungsional juga dapat memberi manfaat yang lebih luas seperti mencegah kecelakaan kerja melalui penurunan risiko jatuh. ${ }^{15}$ Cedera yang dapat timbul akibat kecelakaan kerja tentu memberi dampak yang tidak baik bagi aktivitas petani wanita. 


\section{Keterbatasan Penelitian}

Pada saat melakukan penelitian ada berbagai keterbatasan penelitian yang dihadapi oleh peneliti, di antaranya adalah: (a) Tidak dilakukan pengukuran tinggi badan, berat badan, IMT. (b) Ukuran bola yang dipakai tidak sesuai dengan standar pemakaian ball exercise, yaitu tinggi badan 142 menggunakan bola berukuran $45 \mathrm{~cm}$, tinggi badan $142-162 \mathrm{~cm}$ menggunakan bola berukuran $55 \mathrm{~cm}$, tinggi badan $162-177 \mathrm{~cm}$ menggunakan bola berukuran $65 \mathrm{~cm}$, dan tinggi badan $177-193 \mathrm{~cm}$ menggunakan bola berukuran $75 \mathrm{~cm} .{ }^{16}$ Sedangkan bola yang di gunakan adalah energetics dengan diameter $65 \mathrm{~cm}$. (c) Tidak dilakukan pengukuran kekuatan otot pada responden sehingga faktor ini dapat menjadi faktor pengganggu karena petani tentunya melakukan kegiatan harian yang berbedabeda. Selain dari itu intervensi juga hanya dilakukan selama 4 minggu sehingga hasil yang diperoleh tidak signifikan. (d) Terdapat beberapa pertanyaan pada modified ODI yang kemungkinan tetap terpilih, namun skornya tidak sesuai dengan kondisi petani, misalnya kehidupan sosial.

\section{SIMPULAN}

1. Core stability exercise dapat meningkatkan LGS pada kasus LBP non spesifik petani di Kota Tomohon

2. Core stability exercise dapat menurunkan disabilitas lumbal pada kasus LBP non spesifik petani di Kota Tomohon

3. Penambahan Swiss ball pada core stability exercise dapat meningkatkan LGS pada kasus LBP non spesifik petani di Kota Tomohon

4. Penambahan Swiss ball pada core stability exercise dapat menurunkan disabilitas lumbal pada kasus LBP non spesifik petani di Kota Tomohon

5. Tidak ditemukan perbedaan yang bermakna antara penambahan Swiss ball pada core stability exercise dan core stability exercise dalam meningkatkan LGS pada kasus LBP non spesifik petani di Kota Tomohon
6. Tidak ditemukan perbedaan yang bermakna antara penambahan Swiss ball pada core stability exercise dan core stability exercise dalam menurunkan disabilitas lumbal pada kasus LBP non spesifik petani di Kota Tomohon

\section{SARAN}

1. Melakukan kontrol terhadap variabel pengganggu seperti pemakaian obatobatan penghilang rasa nyeri dan aktivitas fisik dari subjek penelitian.

2. Waktu penelitian dapat diperpanjang menjadi 12 Minggu/ 3 bulan dengan frekuensi latihan 5 kali per minggu, untuk mencapai hasil yang lebih maksimal. Dimulai dari Fase pengenalan, yaitu reaktivasi dan re-edukasi otot tranversus abdominis dan multifidus dengan 3 teknik dasar yaitu hollowing, abdominal braching dan pelvic tilt exercise. Kemudian fase adaptasi, latihan yang diberikan melibatkan otot-otot core global dan segmental, memberikan peningkatan beban dan repetisi untuk meningkatkan kekuatan dan aktivitas fungsional. Terakhir adalah fase refleks, untuk melakukan latihan core yang lebih kompleks.

3. Penambahan Swiss ball pada core stability exercise dan core stability exercise terbukti dapat meningkatkan LGS lumbal dan menurunkan disabilitas lumbal pada petani dengan kondisi LBP non spesifik, maka penulis menyarankan untuk dapat menggunakan ke dua modalitas tersebut pada praktek-praktek layanan fisioterapi.

\section{DAFTAR PUSTAKA}

1. Malonda C. E, Paul A.T Kawatu, dan Diana V. D. 2016. Gambaran Posisi Kerja dan Keluhan Gangguan Musculoskeletal pada Petani Padi di Desa Kiawa Satu Barat, Kecamatan Kawangkoan Utara. Jurnal Ilmiah Farmasi. FKM UNSRAT Manado. Sulawesi Utara. Vol.5. hal. 267272.

2. Paliyama, J.M., 2003. Perbandingan Efek Terapi Arus Interferensi dengan TENS 
dalam Pengurangan Nyeri Punggung Bawah Muskuloskeletal. FK Undip Semarang, Semarang. hal. 13.

3. Pratiwi H. M., Yuliani S., Bina K., dan Martini. 2009. Beberapa Faktor Yang Berpengaruh Terhadap Keluhan Nyeri Pinggang Bawah Pada Penjual Jamu Gendon. Jurnal Promosi Kesehatan Indonesia, Semarang. Vol.4. hal. 61-67.

4. Riskesdas. 2013. Laporan Hasil Riset Kesehatan Dasar Nasional. Jakarta: Badan Penelitian dan Pengembangan Kesehatan. Available at: URL: www. depkes.go.id /resources/download/general/Hasil\%20Ri skesdas\%202013.pdf

5. BPS Kota Tomohon. 2013. Hasil Sensus Pertanian 2013. [dikutip pada 10 Jan. 2018]. Available at: URL: http://tomohonkota.bps.go.id

6. Wicaksono, B. 2011. Faktor Yang Berhubungan Dengan Gangguan Nyeri Punggung Bawah Pada Bidan Saat Menolong Proses Persalinan (Studi di RSUD Bhakti Dharma Husada Surabaya). Skripsi. Surabaya: Fakultas Kesehatan Masyarakat Universitas Airlangga. Available from: URL:http://journal.unair. ac.id/downloadfull/KKLK5161f7e53d2d 60fullabstract.pdf

7. Pocock S. J. (2008). Clinical Trials: A Practical Approach. A Wiley Medical Publication. John Wiley \& Sons. New York. p. 128-129.

8. Rubenstein Irv. 2005. Exercise idea for core strengthening. Visual Health Information.

9. Sekendis B, Cug M, Korkusuz F. 2010. Effects of Swiss-Ball Core Strength Training on Strength, Endurance, Flexibility, and Balance in Sedentary Women. Journal of Strength and Conditioning Research. Australia. Vol.11. p. 3032-3040.

10. Suresh B.R.A., Jarome E., and Kumar S. N., 2015. Effects of core stabilization program and convensional exercise in the management of patients with chronic mechanical low back pain. International Journal of Physiotherapy. Andhra Pradesh, India. Vol.2. p. 441-447.

11. Kisner Carolyn, and Lynn A. C. 2014. Terapi Latihan Dasar dan Teknik. Volume 2, Edisi 6. Penerbit Buku Kedokteran. Jakarta. Vol.2, Ed.6. hal. 351-441. 528-530.

12. Munawwarah M., dan Wahyudin. 2009. Perbedaan Efek Massage dan Swiss Ball Exercise pada Kondisi Spondyloarthrosis Lumbal. Jurnal Fisioterapi. Vol.9, No.1. hal. 39-40.

13. Raj K.T., and Bhumika.K. 2016. Efficacy of floor stabilization exercises and Swiss Ball exercises on patients with nonspecific low back ache and to assess QOL of patients with low back ache- A comparative study. International Journal of Physiotherapy. Andhra Pradesh, India. Vol.4. p. 10542-10547.

14. Balakrishnan R, Eman Y, and Mohamad F. B. M. 2016. Effectiveness of the core stabilisation exercise on floor and Swiss ball on individual with non-Specific low back pain. International Journal of Physical Education, Sports and Health, Malaysia. Vol. 3. p. 347-356.

15. Mahendra, I.G.P.W., Andayani, N.L.N., Dinata, I.M.K. 2016. Pemberian Otago Home Exercise Programme Lebih Baik dalam Mengurangi Risiko Jatuh daripada Balance Strategy Exercise pada Lansia di Tabanan. Majalah Ilmiah Fisioterapi Indonesia. Vol.3, No.1

16. Shiel C. 2016. What you need to know about Physio Balls. (Online Article). [cited 2018 July 8]. Available from: URL: http://www.shielphysio.com/ content/Wh at-you-need-to-know-about-Physio-Balls. Pdf 